\title{
Environmental regulation of individual depth on a cod spawning ground
}

\author{
Justin J. Meager ${ }^{1, *}$, Jon Egil Skjæraasen ${ }^{1,2}$, Ørjan Karlsen ${ }^{2}$, Svein Løkkeborg ${ }^{2}$, \\ Ian Mayer ${ }^{3}$, Kathrine Michalsen ${ }^{2}$, Trygve Nilsen ${ }^{4}$, Anders Fernö ${ }^{1,2}$ \\ ${ }^{1}$ Department of Biology, and ${ }^{4}$ Department of Mathematics, University of Bergen, 5020 Bergen, Norway \\ ${ }^{2}$ Institute of Marine Research, 5817 Bergen, Norway \\ ${ }^{3}$ Norwegian School of Veterinary Science, PO Box 8146, 0033 Oslo, Norway
}

\begin{abstract}
Fine-scale characteristics of spawning grounds may provide the opportunity for cod Gadus morhua L. to regulate their external environment by adjusting their depth. Ultrasonic telemetry was used to study how the environment influenced the depth-related behaviour of individual wild and farmed cod on a spawning ground. Of the environmental predictors examined, temperature explained most variation in depth (best predictor in 16 of 21 fish). A decrease in surface-water temperature was accompanied by a pronounced reduction in daily maximum depth of nearly half the fish examined and movement to a shallower area of the spawning ground. Wind and light (after controlling for diel periodicity) had a comparably limited and variable influence on fish depth. Some of the vertical movements seemed to be associated with feeding rather than spawning activity; wild females with diel vertical migrations (DVMs) had poorer condition than wild females with no DVMs, and DVMs were absent in farmed females in better condition. Generally, there were no clear differences in responses to the environment between wild and farmed cod. The ability of cod to regulate their external environment by changing their depth was likely to have been limited by the location of the spawning shoal at the seafloor.
\end{abstract}

KEY WORDS: Broadcast spawners $\cdot$ Individual depth $\cdot$ Climate change $\cdot$ Mating systems

\section{INTRODUCTION}

The geographical location of breeding sites is in general associated with conditions that maximise fitness (Schmidt 2004, Parejo et al. 2007). In the case of broadcast spawners like Atlantic cod Gadus morhua L., spawning grounds are believed to be associated with areas that enhance survival of larvae (Hutchings et al. 1993). For the migratory Northeast Arctic cod, reproducing at the main spawning grounds of Lofoten ensures that gametes are released into the relatively warm North Atlantic current where larvae are transported northwards into the Barents Sea (Bergstad et al. 1987). This ensures rapid growth and enhanced survival of larvae (Bergstad et al. 1987).
For more resident cod populations, a common denominator of spawning sites is that they seem to occur in areas with high retention of early life stages (Hutchings et al. 1993). This suggests that (1) the locations of spawning grounds are not arbitrary but have been 'chosen' through the evolutionary process and (2) if for whatever reason a spawning site should become unsuitable, other suitable habitats might not be found in the immediate vicinity. Strong fidelity to very localised spawning grounds has in fact been observed in cod (Skjæraasen et al. 2011).

Fine-scale heterogeneity of environmental conditions of spawning grounds may provide the opportunity for cod to maximise their reproductive output by behavioural regulation of their external environ- 
ment. The marine environment often has pronounced vertical gradients in temperature, water currents and light that can vary predictably over diel, tidal and seasonal time cycles. Fish may therefore adjust their depth to avoid extreme conditions or to select microhabitats with conditions favourable for physiological performance or reproductive success. Temperature has important consequences for oocyte maturation in female cod (Kjesbu et al. 2010) and survival and development of gametes and larvae (Otterlei et al. 1999, Bradbury et al. 2001). Wind- and tidal-driven currents affect both the dispersal of fertilised eggs and larvae (Ottersen \& Sundby 1995) and the energetic cost of swimming or maintaining position (Arnold et al. 1994). Light controls the timing of the spawning activity of cod over seasonal (Hansen et al. 2001, Skjæraasen et al. 2004) and diel time scales in captive cod (Brawn 1961, Kjesbu 1989).

Changes in the state and behaviour of individual fish over the spawning season may also influence depth preference. The inter-batch interval of cod females is highly affected by ambient temperature (Kjesbu 1989), and females are likely to seek out a depth that optimises the developmental time of oocytes. The spawning event itself, where a male and female engage in a mating embrace (Brawn 1961, Skjæraasen \& Hutchings 2010), is associated with upwards vertical movement (Meager et al. 2009). Finally, although cod appetite during spawning is believed to be reduced (Fordham \& Trippel 1999, Skjæraasen et al. 2004), cod do feed at this time (Michalsen et al. 2008), and fish may thus undertake foraging excursions towards the surface.

Although such behaviour can be studied through the use of archival tags, problems with positional accuracy generally limit the ability of the most commonly used data-storage tags to determine, for example, distance from the sea floor and the accuracy of positions. Studies of coastal spawning populations are particularly problematic, because they are often either associated with bathymetric features (Marteinsdottir et al. 2000, Ames 2004, Lindholm et al. 2007) or are within heterogeneous inshore habitats such as fjords and inlets (Green \& Wroblewski 2000, Knutsen et al. 2007). Recent experiments designed to examine interactions between farmed and wild cod on a natural spawning ground (Meager et al. 2009, 2010) provided a unique opportunity to explore the responses of individual cod to environmental gradients in detail, as well as the possible effects of previous experience by comparing wild cod and cod raised in captivity. Individual movements of fish were here tracked 3-dimensionally in real-time on the spawning ground using biotelemetry along with simultaneous collection of data on temperature, salinity, light, water current and weather conditions. Expanding on earlier work, we used the tracking data to examine the effect of environmental variables on cod depth, as well as exploring diel vertical migration (DVM) in cod. The results are discussed in terms of their relevance to our understanding of the cod mating system, but also in light of how changing marine environments may affect the suitability of contemporary breeding sites.

\section{MATERIALS AND METHODS}

\section{Study site and experimental fish}

The study was conducted on a known spawning ground of Norwegian coastal cod (Gadus morhua) at Austevoll, western Norway (Fig. 1). The main spawning period at this location is from mid-February to mid-March (information from local fishermen) and from late winter to early spring in the region (Otterå et al. 2006). Wild cod were caught on the spawning ground using nets and fish traps from mid-December 2006 to early February 2007. Farmed fish were obtained from a farm at Fitjar $\left(59^{\circ} 58^{\prime} \mathrm{N}, 5^{\circ} 21^{\prime} \mathrm{E}\right)$ in January 2007, and were F1 progeny of wild fish from Bømlo $\left(59^{\circ} 53^{\prime} \mathrm{N}, 5^{\circ} 5^{\prime} \mathrm{E}\right)$. Fish were kept in 4 seacages (1 $\mathrm{m}$ diameter, $4 \mathrm{~m}$ depth) at a location $2.8 \mathrm{~km}$ from the study site.

In mid-February 2007, fish were anaesthetised with $0.5 \mathrm{~g} \mathrm{l}^{-1}$ Benzocaine. Acoustic tags (full description below) were intraperitoneally implanted into 48 fish (12 from each sex and type). Only fish that were within a week or less of spawning were tagged, based on ultrasound images using a scanner with a 7.5 MHz transducer (Karlsen \& Holm 1994). Fish were also weighed, and total length was measured to calculate Fulton's condition factor ( $K=100 \times$ weight/ length ${ }^{3}$ ).

Fish recovered from surgery in aerated tanks for approximately $1 \mathrm{~h}$. They were then transferred back to the sea-pens for 4 to $5 \mathrm{~d}$ of further recovery before release at the spawning ground on February 19 (Day 0). Fish were tracked for $35 \mathrm{~d}$ until March 25 (Day 34). Shortly after release, spawning by cod at the study site was confirmed by the (1) presence of recently fertilised cod eggs and (2) male mating calls. Male mating calls were identified on 4 occasions during the study using a hydrophone connected to a PC via an amplifier and deployed at approximately $10 \mathrm{~m}$ depth near the centre of the spawning ground. Cod 


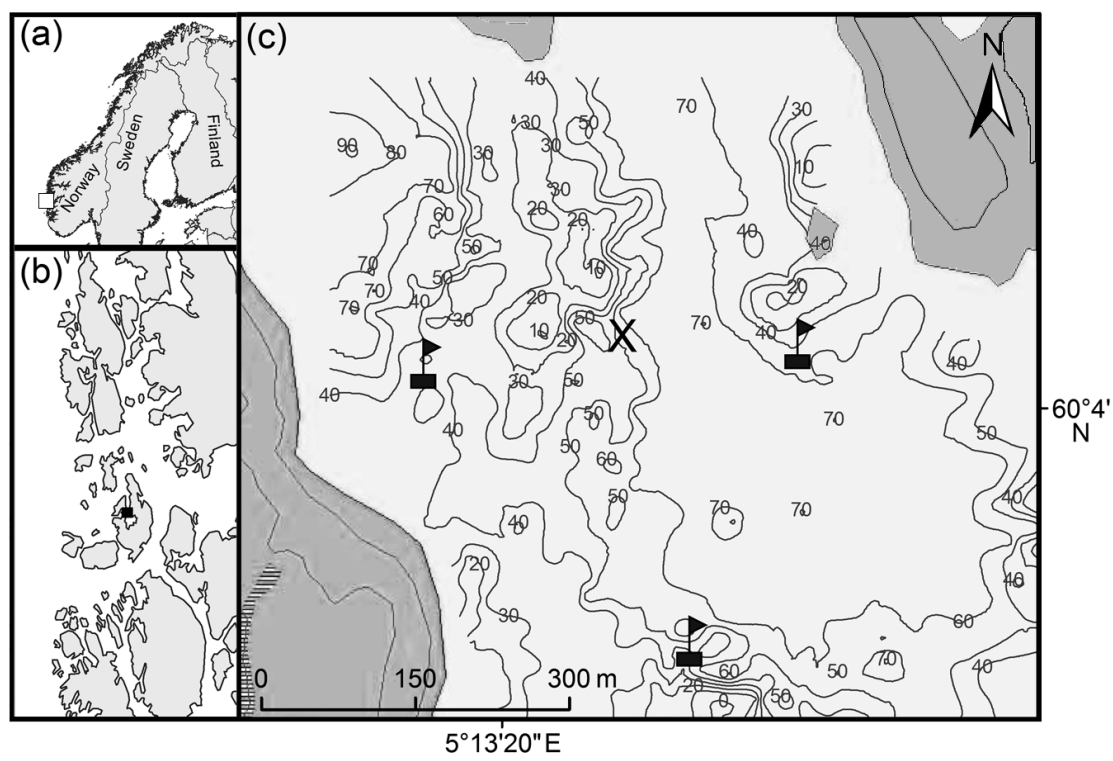

Fig. 1. Study area in (a) Norway and, more specifically, in (b) western Norway. (c) The locations of the hydrophone receivers are indicated by buoy symbols. Depth isobaths $(10 \mathrm{~m})$ were determined by echosounding surveys and interpolated by kriging (Meager et al. 2009). The main spawning aggregation is associated with a rocky slope from 30 to $68 \mathrm{~m}$ depth (X on map c)

eggs were sampled in a plankton net hauled vertically from approximately $50 \mathrm{~m}$ depth (or just above the bottom in shallower waters) at 4 locations on $3 \mathrm{~d}$ in March. Recently fertilised cod eggs were found in all 12 samples. Further information about the wild and farmed fish can be found in Meager et al. (2009, 2010).

\section{Biotelemetry}

We used a radio-linked stationary positioning system (VRAP, Vemco Ltd) that tracked fish from the arrival times of acoustic pulses. This consisted of 3 hydrophone buoys anchored to the seafloor and separated by 310 to $375 \mathrm{~m}$ (Fig. 1), which transmitted data to a base station where fish positions were calculated and displayed in real-time. Two separate tag systems were used: continuous tags (Vemco V16P$4 \mathrm{H})$ that enabled tracking at a high-temporal resolution on a limited number of separate frequencies and individually coded tags (Vemco V16P-4H S256) that allowed a large number of fish to be tracked on the same frequency with longer intervals between positions. Eight continuous tags ( 2 fish from each sex and type) operated on separate frequencies from 51 to $81 \mathrm{kHz}$, and 40 coded tags (10 fish from each sex and type) operated on a frequency of $69 \mathrm{kHz}$. All tags were equipped with a depth-sensor.
Depth data were received throughout the study, but the VRAP system was only able to track the 3-D positions of fish at 1 frequency at a time. We therefore cycled between tracking coded tags for $72 \mathrm{~h}$ and continuous tags for $24 \mathrm{~h}$. Coded tags had a random delay of between 150 and $250 \mathrm{~s}$ between transmissions to minimise collisions between tag signals, which resulted in a sampling interval of between 150 and $300 \mathrm{~s}$ (Meager et al. 2010). Continuous tags transmitted data every second, but were tracked at an interval of $144 \mathrm{~s}$ because the system cycled between the 8 separate tag frequencies, each time listening for $10 \mathrm{~s}$ and uploading data for $8 \mathrm{~s}$.

Positions were based on the average of the $80 \%$ best-aligned pulses and were filtered for errors following Meager et al. (2010). Briefly, positions were retained if they were (1) $<1 \mathrm{~km}$ from the nearest buoy and $(2) \sqrt{D} / p<5$, where $D$ was the standard deviation and $p$ was the number of pulses received in a set of aligned data. Data for the first $24 \mathrm{~h}$ after release were also excluded, because most fish normalised their vertical distribution within the first $24 \mathrm{~h}$ (Meager et al. 2009). Filtered positions were transferred to a GIS.

\section{Physicochemical variables}

Surface irradiance (light) was logged at $10 \mathrm{~min}$ intervals from Day 3 to 34 using a light sensor (LICOR 1000) located on the roof of our base station (1.8 km from the study site). Irradiance at 10, 20 and $30 \mathrm{~m}$ depth was estimated for each time interval from the Beer-Lambert equation, based on measurements of light transmission from water samples taken regularly during the study $(\mathrm{n}=10)$ at the surface and at 10 and $20 \mathrm{~m}$ depth (following Meager et al. 2005). Equipment failure meant that light data were not recorded on Days 5, 6, 22 and 23.

Temperature-salinity-depth (CTD) profiles were also taken regularly from Day $4(\mathrm{n}=23)$ at various locations over the study site (SD200, Saiv). Water current (speed and direction) and temperature were logged at 10 min intervals from Day 0 to 34 by a flowmeter (SD6000, Saiv) at the centre of the study site (30 m depth, $15 \mathrm{~m}$ above the seafloor). Temperature, wind (speed and direction) and precipitation data were obtained at $6 \mathrm{~h}$ intervals (Day 0 to 34 ) for the 
Slåtterøy Fyr station, approximately $12 \mathrm{~km}$ from the study site (data from the Norwegian Meteorological Institute). Wind speed was used as a proxy for windinduced turbulent energy on the surface layer. We did not include directional wind-stress components, because the area was mostly enclosed by steep terrain. Simple moving averages were used to match weather and CTD profiles to the light, temperature and current data that were measured at 10 min intervals.

\section{Data analyses}

Depth data were first filtered to remove tidal noise (i.e. tidal variation in pressure) by taking the residuals from a trigonometric regression (Brockwell \& Davis 2002), using the directional tidal signature measured by the current meter. We then tested for the influence of the environment on the depth-related behaviour of 21 fish with >1100 matched depth and environmental measurements and a minimum of $17 \mathrm{~d}$ of tracking data (Table 1). We did this by fitting the following additive model to the depth data for each individual fish:

Depth $=\alpha+\beta \sin (2 \pi t)+\gamma \cos (2 \pi t)+f_{1}\left(x_{1}\right)+\ldots+f_{\mathrm{k}}\left(x_{\mathrm{k}}\right)+\varepsilon$ where $\varepsilon \sim N\left(0, \sigma^{2}\right)$
The relationship between fish depth and each environmental predictor $\left(x_{1} \ldots x_{k}\right)$ was described by a non-linear smoothing function $\left(f_{1} \ldots f_{\mathrm{k}}\right)$. The trigonometric terms represent a time-series model of diel vertical dynamics with a period of $t$ (time in hours/24) (Pinheiro \& Bates 2000, Crawley 2007), $\alpha$ is the intercept, and $\varepsilon$ is unexplained error with a normal distribution. Eq. (1) was fitted using the generalised additive model (GAM) function of the 'mgcv' library (v.1.7-6 of the R package v.2.13.1; R Development Core Team 2011). The argument gamma $=1.4$ was used as an ad hoc method to avoid overfitting (Wood 2006), and the fit of a given model was checked by standard residual diagnostics and autocorrelation plots ('acf' function) (Faraway 2006).

Salinity was strongly correlated with temperature (r from 0.82 to 0.90 ) and was not included in the analysis to avoid collinearity, whereas there was little correlation between temperature, irradiance and current/wind turbulence (i.e. $\mathrm{r}<0.32$ ). Final depth models for each fish therefore included the best temperature, irradiance and current/turbulence predictors. These variables were determined from 3 correlated sets: (1) air temperature and temperature at 0 , 10, 20 and $30 \mathrm{~m}$ depths; (2) irradiance at the surface and at 10, 20 and $30 \mathrm{~m}$ depths; and (3) wind speed

Table 1. Gadus morhua. Generalised additive models of individual fish depth (W: wild; F: farmed) in relation to the environment. $\mathrm{R}^{2}$ (adj.) is the adjusted $\mathrm{r}^{2}$ of the final model. Bold font denotes the best environment predictor, based on generalisedcross validation scores of single-predictor models. F-values in parentheses test the hypothesis that the predictor has no influence on fish depth $\left({ }^{*} \mathrm{p}<0.1,{ }^{* * *} \mathrm{p}<0.01\right)$. Subscripts indicate the nature of the relationship between fish depth and predictors (+: positive; -: negative; nl: non-linear). Also shown is standard length (SL), condition factor (Fulton's $K$ ), number of days present at the study site (D), number of depth measurements (n) and the mean depth $( \pm \mathrm{SD})$ of each individual fish. Environmental predictors: temperature in the air (Air) and at 0,10, 20 and $30 \mathrm{~m}$ depths; light (irradiance) at 0, 10, 20 and $30 \mathrm{~m}$ depths; wind speed (Wind); and water current at $30 \mathrm{~m}$ depth

\begin{tabular}{|c|c|c|c|c|c|c|c|c|c|}
\hline Fish ID & $\mathrm{SL}(\mathrm{cm})$ & $K$ & $\mathrm{D}$ & $\mathrm{n}$ & Depth (m) & $\mathrm{R}^{2}$ (adj.) & Temperature & Light & Current \\
\hline W@189 & 61 & 0.87 & 34 & 2788 & $17.2 \pm 11.2$ & 0.468 & $10 \mathrm{~m}\left(77.5_{\mathrm{nl}}\right)^{* * *}$ & $0 \mathrm{~m}\left(15.7_{\mathrm{nl}}\right)^{* * *}$ & Wind $\left(3.63_{\mathrm{h}}\right)^{* * *}$ \\
\hline Wo9651 & 66 & 0.98 & 35 & 3528 & $20.9 \pm 13.7$ & 0.542 & $20 \mathrm{~m}\left(102.3_{\mathrm{nl}}\right)^{* * *}$ & $20 \mathrm{~m}\left(18.7_{\mathrm{nl}}\right)^{* * *}$ & $30 \mathrm{~m}\left(67.7_{\mathrm{nl}}\right)^{* * *}$ \\
\hline W@187 & 56 & 1.13 & 23 & 1248 & $27.0 \pm 7.2$ & 0.293 & Air (32.3_) & $10 \mathrm{~m}\left(12.9_{\mathrm{nl}}\right)^{* * *}$ & Wind $\left(9.9_{\mathrm{nl}}\right)^{* * *}$ \\
\hline Wo9652 & 64 & 1.10 & 35 & 1123 & $21.4 \pm 13.7$ & 0.241 & $30 \mathrm{~m}\left(13.5_{+}\right)^{* * *}$ & $10 \mathrm{~m}(5.18 \mathrm{nl})^{* * *}$ & Wind $\left(18.9_{\text {nl }}\right)^{* * *}$ \\
\hline Wo214 & 69 & 1.18 & 30 & 2223 & $32.4 \pm 7.2$ & 0.229 & Air $\left(24.2_{+}\right)^{* * *}$ & $10 \mathrm{~m}\left(27.0_{\mathrm{nl}}\right)^{* * *}$ & Wind $\left(14.7_{\mathrm{nl}}\right)^{* * *}$ \\
\hline Wo'213 & 57 & 1.13 & 31 & 2790 & $39.3 \pm 12.7$ & 0.294 & $\operatorname{Air}\left(29.9_{\mathrm{nl}}\right)^{* * *}$ & $10 \mathrm{~m}\left(34.8_{\mathrm{nl}}\right)^{* * *}$ & Wind $\left(50.3_{\mathrm{nl}}\right)^{* * *}$ \\
\hline W ơ'9659 & 68 & 1.07 & 33 & 3668 & $30.3 \pm 14.8$ & 0.555 & $20 \mathrm{~m}\left(417_{+}\right)^{* * *}$ & $20 \mathrm{~m}\left(14.7_{\mathrm{nl}}\right)^{* * *}$ & $30 \mathrm{~m}\left(18.12_{\mathrm{nl}}\right)^{* * *}$ \\
\hline W ơ'9658 & 63 & 1.07 & 33 & 4052 & $34.0 \pm 14.8$ & 0.515 & Air $\left(290.6_{+}\right)^{* * *}$ & $20 \mathrm{~m}\left(89.2_{-}\right)^{* * *}$ & $30 \mathrm{~m}\left(122.2_{\mathrm{nl}}\right)^{* * *}$ \\
\hline Wơ190 & 70 & 0.99 & 34 & 3558 & $42.4 \pm 9.7$ & 0.483 & $20 \mathrm{~m}\left(174.2_{+}\right)^{* * *}$ & $10 \mathrm{~m}\left(11.2_{\mathrm{nl}}\right)^{* * *}$ & $30 \mathrm{~m}\left(21.2_{+}\right)^{* * *}$ \\
\hline Wơ199 & 61 & 1.14 & 33 & 3151 & $38.7 \pm 7.3$ & 0.390 & Air $\left(46.5 \_\right)^{* * *}$ & $0 \mathrm{~m}\left(11.4_{+}\right)^{* * *}$ & Wind $\left(121.6_{\mathrm{nl}}\right)^{* * *}$ \\
\hline Wơ 198 & 79 & 1.10 & 17 & 1506 & $35.0 \pm 4.3$ & 0.297 & $20 \mathrm{~m}\left(52.1_{\mathrm{nl}}\right)^{* * *}$ & $0 \mathrm{~m}\left(24.4_{-}\right)^{* * *}$ & Wind $\left(22.9_{\mathrm{nl}}\right)^{* * *}$ \\
\hline Wơ'194 & 61 & 0.99 & 28 & 1151 & $47.8 \pm 7.8$ & 0.232 & $30 \mathrm{~m}\left(75.5_{+}\right)^{* * *}$ & $10 \mathrm{~m}\left(4.85_{\mathrm{nl}}\right)^{*}$ & Wind $(8.58 \mathrm{nl})^{* * *}$ \\
\hline Wơ 191 & 63 & 0.96 & 22 & 2412 & $40.9 \pm 5.3$ & 0.131 & $\operatorname{Air}\left(8.68_{+}\right)^{* * *}$ & $0 \mathrm{~m}\left(17.7_{+}\right)^{* * *}$ & Wind $\left(12.8_{\mathrm{nl}}\right)^{* * *}$ \\
\hline Wo'197 & 73 & 1.02 & 23 & 1757 & $47.5 \pm 6.2$ & 0.069 & Air $\left(9.13_{\mathrm{nl}}\right)^{* * *}$ & $10 \mathrm{~m}\left(4.36_{-}\right)^{*}$ & Wind $\left(8.42_{-}\right)^{* * *}$ \\
\hline Fo9657 & 61 & 1.38 & 34 & 2883 & $30.0 \pm 16.2$ & 0.567 & $10 \mathrm{~m}\left(184.2_{\mathrm{nl}}\right)^{* * *}$ & $0 \mathrm{~m}\left(4.3_{\mathrm{nl}}\right)^{* * *}$ & Wind $\left(9.51_{+}\right)^{* * *}$ \\
\hline Fo9656 & 64 & 1.50 & 34 & 2827 & $29.5 \pm 16.1$ & 0.533 & $0 \mathrm{~m}\left(161.0_{+}\right)^{* * *}$ & $0 \mathrm{~m}\left(2.80_{\mathrm{nl}}\right)^{*}$ & Wind $\left(11.5_{+}\right)^{* * *}$ \\
\hline Fᄋ208 & 62 & 1.43 & 30 & 1644 & $29.6 \pm 6.0$ & 0.331 & $30 \mathrm{~m}\left(75.5_{+}\right)^{* * *}$ & $10 \mathrm{~m}(2.99)$ & Wind $\left(21.7_{\mathrm{nl}}\right)^{* * *}$ \\
\hline Fo183 & 62 & 1.32 & 34 & 3662 & $16.5 \pm 2.6$ & 0.151 & $10 \mathrm{~m}\left(34.4_{+}\right)^{* * *}$ & $10 \mathrm{~m}\left(16.2_{+}\right)^{* * *}$ & Wind $\left(16.2_{-}\right)^{* * * *}$ \\
\hline Fơ 9654 & 63 & 1.35 & 33 & 1846 & $26.9 \pm 16.7$ & 0.491 & $20 \mathrm{~m}\left(68.9_{+}\right)^{* * *}$ & $0 \mathrm{~m}\left(9.47_{\mathrm{nl}}\right)^{* * *}$ & Wind $\left(12.45_{+}\right)^{* * *}$ \\
\hline Fơ 9649 & 64 & 1.19 & 35 & 2048 & $26.9 \pm 17.1$ & 0.369 & $0 \mathrm{~m}\left(40.4_{\mathrm{nl}}\right)^{* * *}$ & $0 \mathrm{~m}\left(3.68_{-}\right)^{* * *}$ & Wind $\left(6.78_{+}\right)^{* * *}$ \\
\hline Fo'182 & 59 & 1.32 & 34 & 5869 & $28.0 \pm 3.9$ & 0.143 & $20 \mathrm{~m}\left(\mathbf{8 1 0 . 8}_{+}\right)^{* * * *}$ & $20 \mathrm{~m}\left(23.6_{+}\right)^{* * *}$ & Wind $\left(3.63_{\mathrm{nl}}\right)^{* * *}$ \\
\hline
\end{tabular}


and current strength at $30 \mathrm{~m}$, by comparing generalised cross validation scores (GCV) of single-predictor models.

Initial examination of the depth of individual fish over the study period indicated a general trend of occupying shallower depths after Day 20. We tested this observation with a linear-mixed effect model ('Ime4' library of R), where maximum daily depth was the response variable, and the fixed effects of fish type, sex and time period (before or after Day 20) were explanatory variables. This analysis included only the 21 fish analysed above, and fish identity was included as a random intercept. Nested log-likelihood ratios $\left(G^{2}\right)$ were used to test for the significance of fixed effects and to arrive at the final model.

We then analysed the complete dataset of fish depths from Day 1 to 34 for each individual fish with $>50$ depth observations (32 fish: 6 farmed on, 5 farmed o, 11 wild $0^{\prime \prime}, 10$ wild o). Fish were classed as (1) undergoing DVMs or (2) not undergoing DVMs, based on their main behavioural pattern throughout the study (sensu Neilson \& Perry 1990). This decision was based on (1) sine-cosine coefficients that differed significantly from 0 (i.e. F-test of trigonometric terms in Eq. 1) and (2) significant day-night differences in mean depth exceeding $5 \mathrm{~m}$. We tested criterion (2) by comparing day depth with night depth using paired $t$-tests for each fish. To test the hypothesis that DVMs were related to feeding, and thereby condition, we compared the mean condition factor (Fulton's $K$ ) of fish that underwent DVMs with fish that did not undergo DVMs with Student's $t$-tests, for each sex and type.

\section{RESULTS}

\section{Physicochemical environment}

Mean daily air temperature increased from $0.6^{\circ} \mathrm{C}$ when the fish were released at Day 0 to $6.9^{\circ} \mathrm{C}$ on the final day, but fluctuated throughout the study (Fig. 2). Notably, air temperature declined from Day 21 to 29 and increased again thereafter. Surface water temperatures (i.e. $<20 \mathrm{~m}$ depth) were similar at the start (mean \pm SD: $6.8 \pm 0.8^{\circ} \mathrm{C}$, when first measured on Day 4$)$ and finish of the study $\left(6.3 \pm 0.5^{\circ} \mathrm{C}\right.$, Day 34$)$, (a) Air temperature $\left({ }^{\circ} \mathrm{C}\right)$

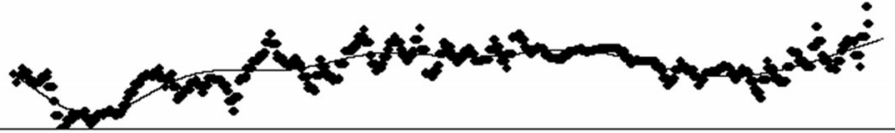

(b) Wind speed $\left(\mathrm{m} \mathrm{s}^{-1}\right)$

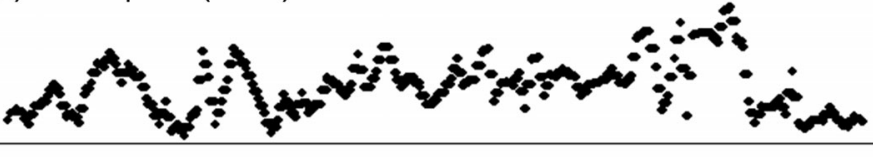

(c) Current $\left(\mathrm{cm} \mathrm{s}^{-1}\right)$

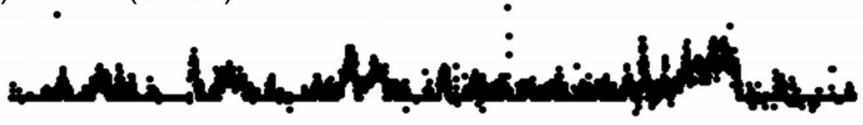

(d) Surface irradiance ( $\left.\mu \mathrm{mol} \mathrm{m}^{-2} \mathrm{~s}^{-1}\right)$ (log transformed)

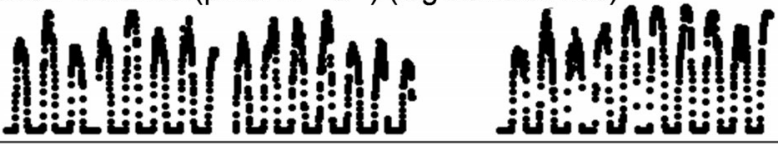

(e) Irradiance at $20 \mathrm{~m}$ depth $\left(\mu \mathrm{mol} \mathrm{m} \mathrm{m}^{-2} \mathrm{~s}^{-1}\right)$ (log transformed)

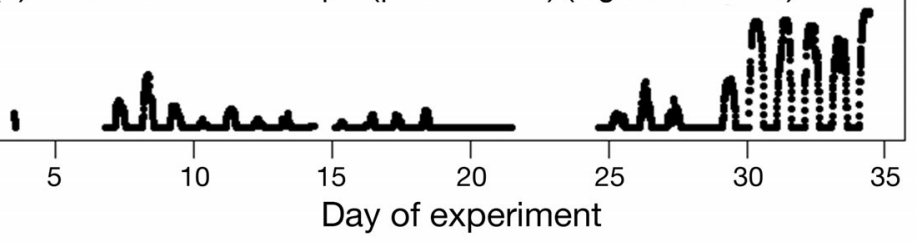

\section{Day of experiment}

Fig 2. (a) Air temperature, (b) wind speed, (c) water current speed (at $30 \mathrm{~m}$ ), d) surface irradiance and (e) irradiance at $20 \mathrm{~m}$ depth. Daily irradiance data additive model was used for the trend line in (a)

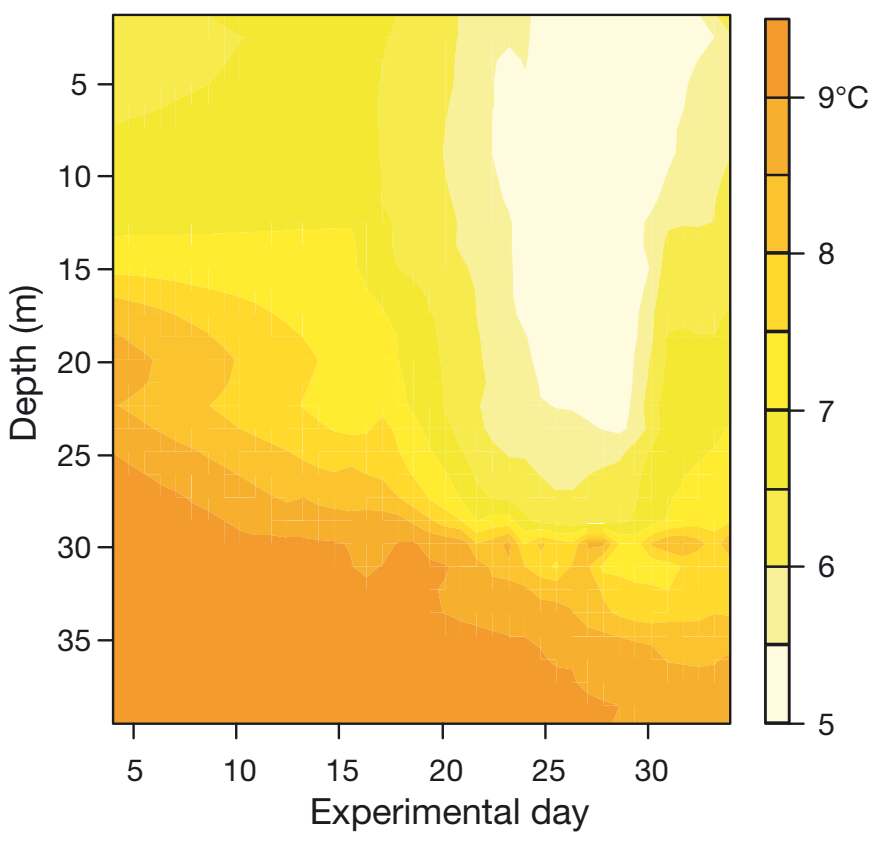

Fig. 3. Temperature-depth profiles from Day 4 to 34. Mean daily temperatures from the current meter were incorporated at $30 \mathrm{~m}$, and data were linearly interpolated ('Akima' package v.0.5-4) 
but declined markedly on Day 22 to a minimum of $5.3 \pm 0.1^{\circ} \mathrm{C}$ on Day 25 (Fig. 3). Temperature was comparatively stable at depths of $30 \mathrm{~m}\left(8.9 \pm 0.6^{\circ} \mathrm{C}\right)$ and deeper (Fig. 3).

Wind speed was variable and reached a peak during a northerly gale on Day 29 (Fig. 2). Current speed at $30 \mathrm{~m}$ depth was generally low $\left(0\right.$ to $6.8 \mathrm{~cm} \mathrm{~s}^{-1}$ ) and predominantly tidally driven (Fig. 2). Salinity was significantly lower in surface waters $(<20 \mathrm{~m}: 31.4 \pm$ 0.1 , mean $\pm \mathrm{SE}$ ) than in deeper waters (20 to $40 \mathrm{~m}$ : $34.9 \pm 0.07$ ) (Student's $t$-test, $\mathrm{p}<0.001$ ). Maximum diurnal irradiance at the water surface varied from 42 to $1437 \mu \mathrm{mol} \mathrm{m}^{-2} \mathrm{~s}^{-1}$ (Fig. 2). Day length ranged from $9 \mathrm{~h}, 29 \mathrm{~min}$ when the fish were released to $12 \mathrm{~h}$, $38 \mathrm{~min}$ at the end of the study.

\section{Environmental predictors of vertical dynamics}

Of the environmental predictors examined (temperature, irradiance, water current and surface wind), temperature explained the most variation in vertical dynamics of 16 of the 21 fish (Table 1). Models in which temperature had a strong influence also had the highest adjusted $\mathrm{r}^{2}$ values (Table 1). In most cases, fish depth was influenced by temperature in surface waters $(<20 \mathrm{~m})$ or a proxy of surface-water temperature (air temperature). Temperature measured at $30 \mathrm{~m}$ depth was the best temperature predictor in only 3 of the 21 fish, and all 3 of these models had adjusted $r^{2}$ values of $<0.4$ (Table 1). Twelve fish were deeper when temperature was higher (i.e. ' + ' coefficients in Table 1), whereas 2 fish were shallower at higher temperatures. The remaining 7 fish had non-linear responses to temperature over the range of temperatures encountered.

Wind speed was the next best environmental predictor after temperature in $17 \mathrm{fish}$, and the best predictor in 3 of the 21 fish. However, adjusted $\mathrm{r}^{2}$ values were low $(<0.4)$ in all 3 of these cases, indicating that considerable variation in vertical dynamics was not accounted for. Overall, 5 fish migrated deeper when surface conditions were more turbulent (i.e. higher wind), 2 did the opposite, and the remaining fish had a non-linear depth response to wind (Table 1).

Light irradiance was the best predictor in only 2 fish, and in both cases the adjusted $\mathrm{r}^{2}$ values were $<0.3$ (Table 1). The first fish (W\$214) had a non-linear response to light irradiance at $10 \mathrm{~m}$ depth, whereas the second (Wo'191) preferred deeper depths when surface irradiance was elevated (Table 1).

\section{Vertical dynamics of individuals}

Fish reduced their maximum daily depth significantly after Day $20\left(G^{2}=8.5, \mathrm{p}=0.004 ; t=8.3, \mathrm{p}<\right.$ $0.0001)$, and this change was more pronounced in females than in males $\left(G^{2}=17.6, \mathrm{p}<0.0001 ; t=6.6\right.$, $p=0.003$ ). Maximum daily depth was not influenced by fish type (i.e. wild or farmed) (sex $\times$ type interaction: $G^{2}=1.7, \mathrm{p}=0.2$; type $\times$ time period interaction: $G^{2}=2.11, \mathrm{p}=0.15$; sex $\times$ time period $\times$ type: $G^{2}=$ $0.09, \mathrm{p}=0.77$ ). Visits to shallow water also increased after Day 30 (see examples in Fig. 4).

Examination of the horizontal positions of fish revealed that an area of seafloor on the western side
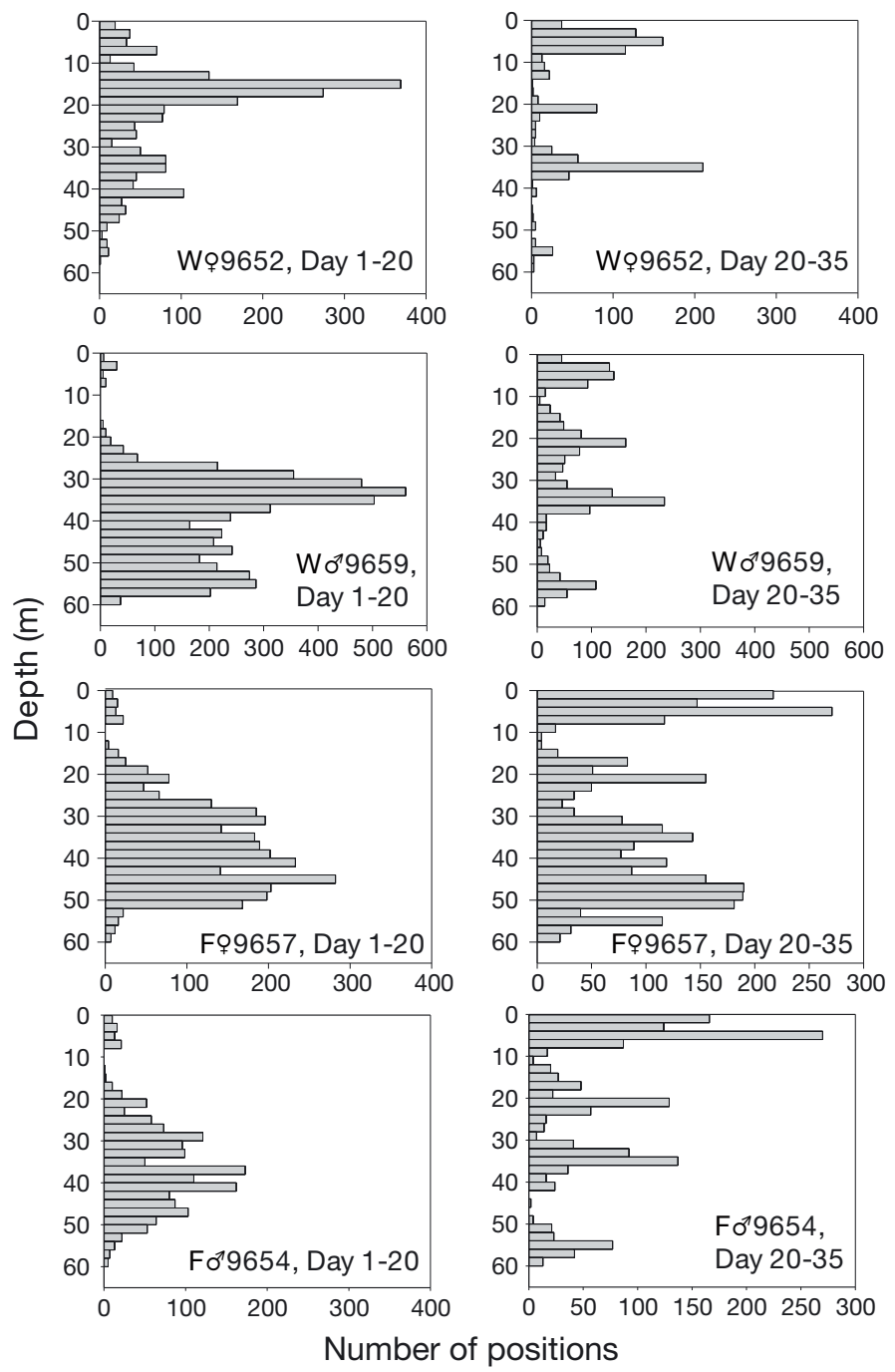

Fig. 4. Gadus morhua. Frequency histograms of fish depth before and after Day 20. An example is provided of a fish from each type (farmed or wild) and sex that demonstrated more frequent visits to shallow water after Day 20 (Wo9652, $\mathrm{n}=$ 4360; Wơ 9659, $\mathrm{n}=$ 6896; Fo 9657, $\mathrm{n}=$ 4456; Fơ'9654, $\mathrm{n}=$ 4459). W: wild; F: farmed 

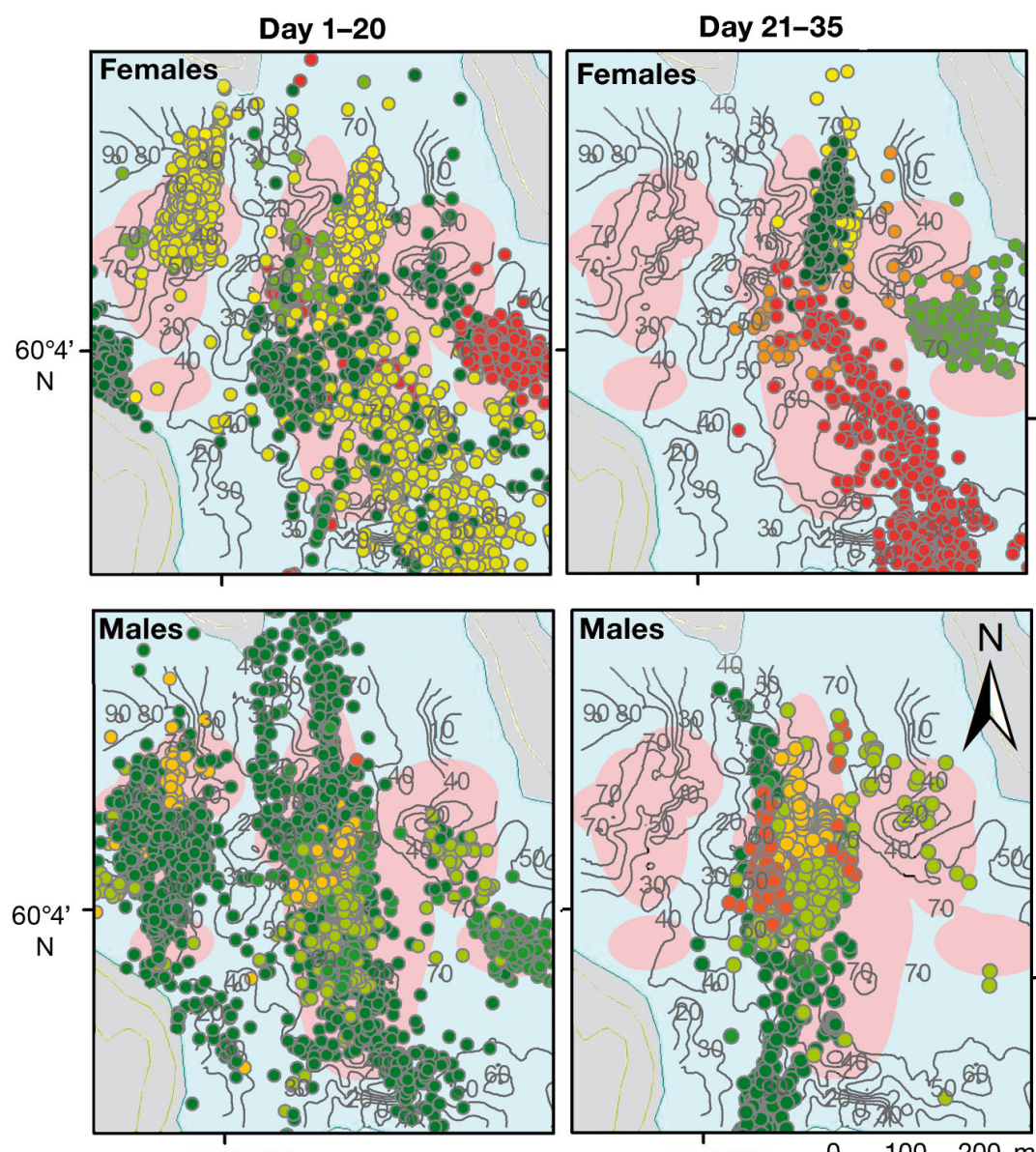

5०13'20'”

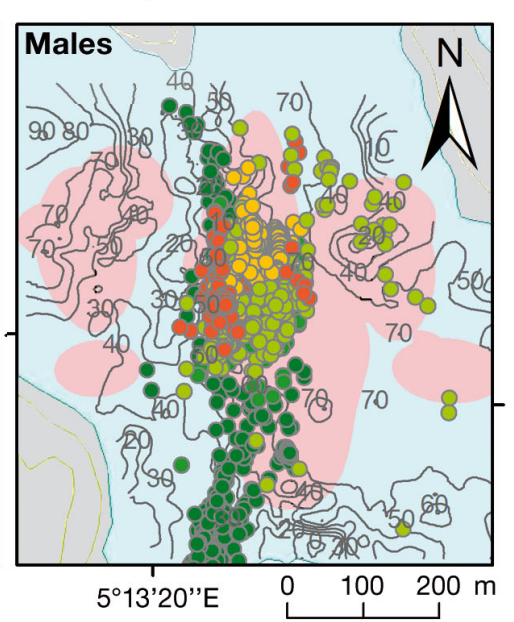

Fig. 5. Gadus morhua. Change in horizontal distribution between the first (Day 1 to 20) and second (Day 21 to Day 35) time periods of the study. Only fish with $>20$ positions in each period are shown. For each sex, position fixes are colour-coded by individual fish. The pink area delineates the 'spawning arena' defined as the total area covered by the core usage areas of wild males (Meager et al. 2010)

of the spawning ground (from 50 to $80 \mathrm{~m}$ depth) used frequently prior to Day 20 was rarely used after Day 20 (see examples in Fig. 5). After Day 20, wild males were mostly confined to an area of seafloor between 25 and $40 \mathrm{~m}$ depth along a rocky slope in the centre of the spawning ground (Fig. 5).

\section{Diel vertical migrations}

DVMs were characterised by ascents well before sunset (i.e. before the end of civil twilight) followed by descents before sunrise (either during civil or nautical twilight) and were evident in 5 wild females (3 examples shown in Fig. 6), although the exact timing varied over time and between individuals. DVMs were also observed in 2 wild and 3 farmed males, but were absent in farmed females. Even wild females that had DVMs with strong $24 \mathrm{~h}$ synchronicity did not show this pattern for the entire study. For example, W\$189 underwent DVMs for $38 \%$ of the days that it was resident (i.e. 13 of 34 d), and W $\$ 192$ underwent DVMs for $42 \%$ of the days it was resident (8 of $19 \mathrm{~d}$ ) (Fig. 6).

Only the wild female group had enough individuals with DVMs and observations per individual $(n>100)$ for statistical comparison. Wild females with DVMs had significantly poorer condition (mean $K \pm \mathrm{SE}$ : $0.98 \pm 0.04)$ than females with no DVMs $(1.13 \pm 0.01)\left(t_{8}=3.64, \mathrm{n}_{1}=5, \mathrm{n}_{2}=5, \mathrm{p}=\right.$ 0.007). Farmed males with DVMs also tended to have poorer condition $(1.19 \pm$ $0.03, \mathrm{n}=3$ ) than farmed males not demonstrating this behaviour $(1.27 \pm 0.02, \mathrm{n}=$ 6 ), whereas condition was similar for wild males with $(1.07 \pm 0.003, \mathrm{n}=2)$ and without DVMs $(1.04 \pm 0.02, \mathrm{n}=9)$.

\section{DISCUSSION}

\section{Environmental regulators: temperature, light and wind}

Our results indicated that cod responded to fine-scale characteristics of the spawning ground and adjusted their depth when the ambient temperature changed. This was the case in $76 \%$ of the fish examined, and in fish of both types and sexes. Cod are known to be very sensitive to temperature during the spawning season (Righton et al. 2010), when they have a narrow thermal 'window' because of the aerobic demands of large reproductive organs (Pörtner \& Farrell 2008, Pörtner et al. 2008, Kjesbu et al. 2010). Temperature also plays a fundamental role in determining the quality of oocytes released (van der Meeren \& Ivannikov 2006) and the subsequent survival and growth of eggs and larvae (Otterlei et al. 1999, Bradbury et al. 2001).

Further, the results of our study suggest the mating system of cod may have limited their ability to behaviourally thermoregulate. Despite the fact that temperatures were $2^{\circ} \mathrm{C}$ cooler in the surface layer at the start of the study, wild males shoaled near the seafloor and only briefly visited the surface layer. These male shoals are typically formed during the spawning period (Morgan \& Trippel 1996, Nordeide 1998, Meager 

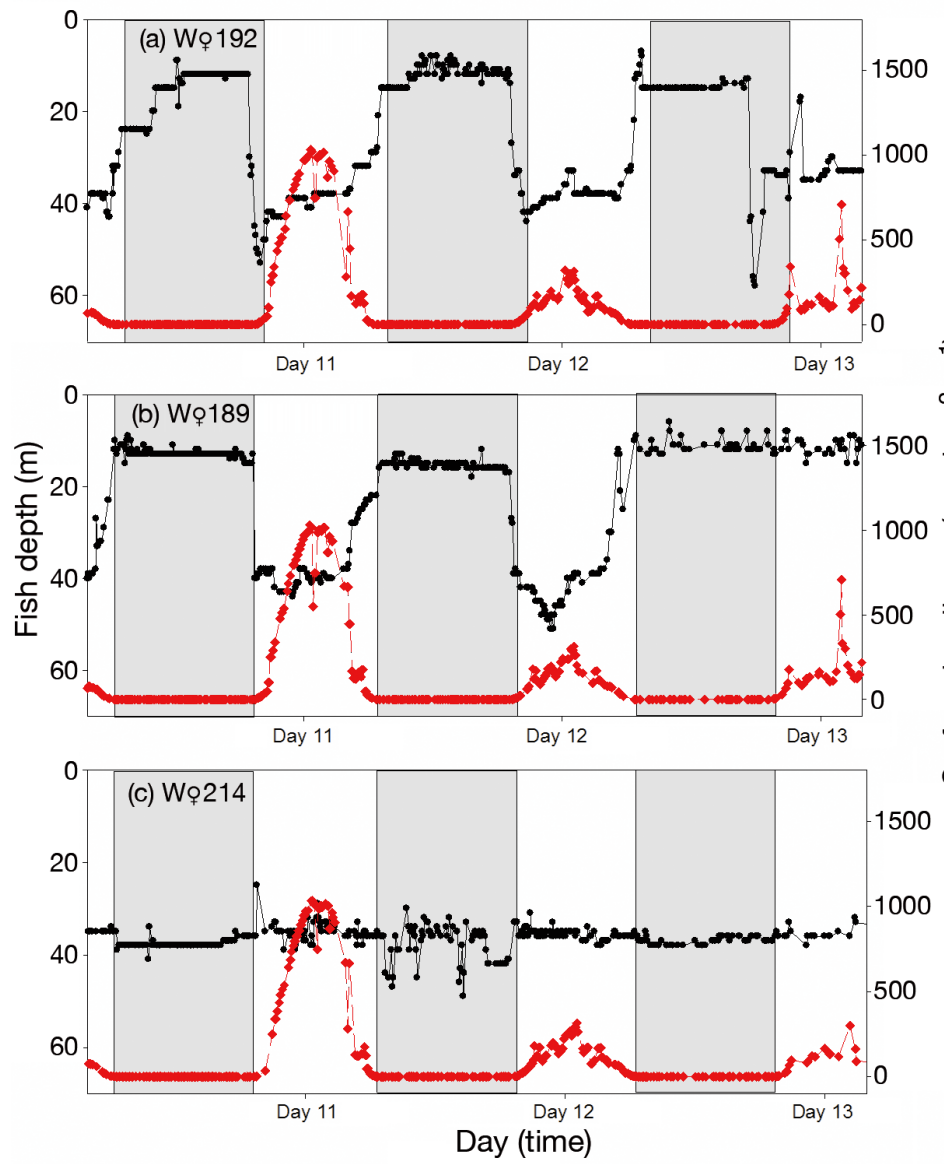

Fig. 6. Gadus morhua. Individual variation in diel vertical migrations (DVMs) from Day 10 to 13 for (a) a wild female exhibiting 3 consecutive DVMs, (b) a wild female exhibiting 2 consecutive DVMs and (c) a wild female not exhibiting DVMs. Black circles: fish depth $(\mathrm{m})$; red diamonds: surface irradiance; shaded boxes: night. Ticks on $\mathrm{x}$-axis are at 12:00 $\mathrm{h}$

et al. 2009) and are often associated with specific bathymetric features (Marteinsdottir et al. 2000, Ames 2004, Lindholm et al. 2007, present study). Here males are thought to compete (Rowe et al. 2008, Skjæraasen et al. 2010) for access to visiting females (Hutchings et al. 1999, Nordeide \& Folstad 2000). This behaviour probably limited males to positions near the seafloor, which was almost entirely within the warmer bottom layer at the start of the study. The effects of elevated temperature on male gamete quality in cod are not well understood (Purchase et al. 2010), but may not be as adverse as those observed for females (van der Meeren \& Ivannikov 2006). Even so, on Day 20 there was a pronounced downwelling of cooler surface water (Fig. 3) to shallower areas of the seafloor on the spawning ground (Fig. 1), causing males to subsequently move to these shallower areas (Fig. 5).

In contrast, wild females either spent most time in the surface layer and occasionally migrated deeper or underwent frequent movements between the bot- tom and surface layers (Meager et al. 2009, 2010). One explanation for this behaviour may be that they prefer the cooler temperatures at the surface in order to optimise egg quality (van der Meeren \& Ivannikov 2006) and the interval between spawning batches (Kjesbu 1989), in between visits to the spawning shoal at the seafloor. Staying at the surface may also allow females to avoid male harassment between spawning events (Meager et al. 2009). It is also possible that the warmer temperatures at the start of the study facilitated DVMs of greater magnitude because of enhanced buoyancy regulation. The extent of rapid vertical movements in cod is restricted by their physoclist swimbladder, but the normally slow process of secreting gas into the swimbladder is much faster at higher temperatures (Harden Jones \& Scholes 1985).

Climate change has been predicted to drive the distribution of cod northwards (Perry et al. 2005, Grebmeier et al. 2006, Sundby \& Nakken 2008). Yet non-migratory populations, such as Norwegian coastal cod, exhibit strong fidelity to local spawning sites (Hutchings et al. 1993, Robichaud \& Rose 2001, Skjæraasen et al. 2011). It is not given that these populations will migrate to new spawning areas, or even that suitable alternatives will be available across latitudes. Sharp vertical gradients in temperature allow fish to behaviourally adjust to elevated temperatures on a spawning ground in a manner consistent with our observations. However, this ability is likely to be limited by the vertical temperature range available on the spawning ground and the bathymetry of the spawning ground. In the case of our study, the rocky slope at the centre of the spawning ground (Figs. $1 \& 5$ ) provided the opportunity for males associated with the seafloor to adjust their temperature.

Surface wind also influenced the depth of fish on the spawning ground in our study. The response of cod to wind depended on the wind strength and varied between individuals, but, in general, strong winds made the fish move deeper. Cod have often been observed to reduce swimming activity and spend more time near the seafloor when tidal currents are strong (Løkkeborg et al. 1989, Arnold et al. 1994, Michalsen et al. 1996, Aglen et al. 1999). The tidally driven current at $30 \mathrm{~m}$ depth was generally weak in the present study, but surface winds were sometimes strong. Temporally and spatially variable surface currents driven by local wind stress (Ibrayev et al. 2010) 
and wave movements in shallow waters could result in turbulent conditions demanding frequent orientation adjustments by the fish, with possible negative effects on reproductive behaviour.

Light had comparatively little influence on the vertical movements of cod and was the best predictor of the depth of only 2 of the 21 fish. This is likely to be because the periodic components in our statistical model (Eq. 1) explain much of the association between vertical dynamics and light. This supports the notion that light acts as a signal controlling the timing of DVMs in cod, rather than the magnitude of depth movements directly (Blaxter 1975, Neilson \& Perry 1990).

Non-additive and complex interactions between different abiotic parameters such as wind and temperature can also influence the dynamics of fish populations (Ciannelli et al. 2004). For example, the rapid decline in water temperature towards the end of the study was likely to have been associated with downwelling of cooler surface waters from turbulent mixing following strong winds - despite the fact that wind strength and temperature were not significantly correlated. Interactive and synergistic environmental drivers of behaviour on spawning grounds should be the focus of future studies.

\section{Diel vertical dynamics: feeding and spawning}

In general, fish that exhibited diel depth changes moved closer to the surface at night (i.e. Type I DVM; Neilson \& Perry 1990), although this varied with location on the spawning ground and the type and sex of fish. Our results suggest that at least some of these vertical movements on spawning grounds may have been associated with foraging. Although most fish had vertical movements that were quite variable throughout day and night, 5 of the 10 wild females examined had DVMs that were closely synchronised to dusk ascent and dawn descent. These fish also had poorer condition than the other wild females. DVMs are closely related to foraging behaviour in cod (Turuk 1973, Mattson 1990, Strand \& Huse 2007) and are more common in cod in poorer condition (Turuk 1973, present study). These results concur with previous studies showing that, while male cod have little appetite during final maturation and spawning (Fordham \& Trippel 1999, Skjæraasen et al. 2004), females may continue foraging during the spawning period (Michalsen et al. 2008). Notably, DVMs were absent in farmed females with higher condition values and thus presumably lower energetic requirements than wild females. Some feeding activity at the end of the study may also have been evident in 2 wild males (Wo'9659, Wo $0^{1} 9658$ ), because they spent much of their time in very shallow water $(<10 \mathrm{~m})$ after Day 33.

It is also likely that at least some of the vertical movements we recorded in our study were associated with the spawning event itself. Vertical ascents have previously been linked with spawning in groups of captive cod (Hutchings et al. 1999, Meager et al. 2009) and in acoustic studies of wild fish (Rose 1993).

\section{Concluding remarks}

Fine-scale characteristics of the local environment influenced the depth of fish on the spawning ground. Fish demonstrated a response to temperature, but only when the cooler water penetrated to the seafloor on the spawning ground. Strong winds resulting in turbulent conditions generally made the fish move into deeper waters and may have facilitated the downwelling of cooler waters. The ability of cod to respond to changes in conditions was likely to have been constrained by their mating system and the range of conditions available on the spawning ground.

Earlier work has demonstrated that temperature increases such as those predicted from climate change are likely to have an adverse impact on ovarian maturation, gamete quality and larval survival of Norwegian coastal cod (e.g. Otterlei et al. 1999, van der Meeren \& Ivannikov 2006, Kjesbu et al. 2010). Here, we show that vertical environmental gradients may provide cod with some opportunities to select a favourable environment or reduce thermal stress by changing their depth, but that this is likely to be limited by their mating system and the fine-scale characteristics of the spawning ground. This suggests that climate change may not equally impact different spawning grounds in a given region.

Spawning grounds featuring pronounced bathymetric relief, such as the one in this study, provide bottom-associated spawning shoals with the opportunity to respond to vertical environmental gradients by moving along the bathymetric relief. Further research into how the physical structure of the seafloor at different spawning grounds is linked to the formation of spawning shoals and thereby the reproductive success of fish is warranted to understand the impact of climatic change on localised populations of marine fish.

Acknowledgements. Financial support was provided by the Norwegian Research Council Project Nos. 172649/S40 and 177744/V40. Experimental procedures complied with the 
Norwegian Council for Animal Research. We thank Stig Ove Utskot for valuable advice and help in the field. Our gratitude also extends to the IMR staff at Austevoll and in the Fish Capture Division, volunteers who helped in the field, and to Knut Heimark and the other local fishermen at Osen.

\section{LITERATURE CITED}

Aglen A, Engås A, Huse I, Michalsen K, Stensholt BK (1999) How vertical fish distribution may affect survey results. ICES J Mar Sci 56:345-360

Ames EP (2004) Atlantic cod stock structure in the Gulf of Maine. Fisheries (Bethesda, Md) 29:10-28

> Arnold GP, Walker MG, Emerson LS, Holford BH (1994) Movements of cod (Gadus morhua L.) in relation to the tidal streams in the southern North Sea. ICES J Mar Sci 51:207-232

> Bergstad OA, Jorgensen T, Dragesund O (1987) Life history and ecology of the gadoid resources of the Barents Sea. Fish Res 5:119-161

Blaxter JHS (1975) The role of light in the vertical migration of fish-a review. In: Evans GC, Bainbridge R, Rackham O (eds) Light as an ecological factor. II. Blackwell Scientific Publications, Oxford

Bradbury IR, Snelgrove PVR, Fraser S (2001) The influence of temperature on advective loss of Atlantic cod (Gadus morhua) eggs from the inshore environment. Fish Oceanogr 10:342-352

Brawn VM (1961) Reproductive behaviour of the cod (Gadus callarias L.). Behaviour 18:177-197

Brockwell PJ, Davis RA (2002) Introduction to time series and forecasting. Springer-Verlag, New York, NY

Ciannelli L, Chan KS, Bailey KM, Stenseth NC (2004) Nonadditive effects of the environment on the survival of a large marine fish population. Ecology 85:3418-3427

Crawley MJ (2007) The R book. Wiley, Chichester

Faraway JJ (2006) Extending the linear model with R: generalized linear, mixed effects and nonparametric regression models. Chapman \& Hall/CRC, Boca Raton, FL

> Fordham SE, Trippel EA (1999) Feeding behaviour of cod (Gadus morhua) in relation to spawning. J Appl Ichthyol 15:1-9

Grebmeier JM, Overland JE, Moore SE, Farley EV and others (2006) A major ecosystem shift in the northern Bering Sea. Science 311:1461-1464

Green JM, Wroblewski JS (2000) Movement patterns of Atlantic cod in Gilbert Bay, Labrador: evidence for bay residency and spawning site fidelity. J Mar Biol Assoc UK 80:1077-1085

> Hansen T, Karlsen O, Taranger GL, Hemre GI, Holm JC, Kjesbu OS (2001) Growth, gonadal development and spawning time of Atlantic cod (Gadus morhua) reared under different photoperiods. Aquaculture 203:51-67

- Harden Jones FR, Scholes P (1985) Gas secretion and reabsorption in the swimbladder of the cod Gadus morhua. J Comp Physiol B 155:319-331

> Hutchings JA, Myers RA, Lilly GR (1993) Geographicvariation in the spawning of Atlantic cod, Gadus morhua, in the Northwest Atlantic. Can J Fish Aquat Sci 50: 2457-2467

Hutchings JA, Bishop TD, McGregor-Shaw CR (1999) Spawning behaviour of Atlantic cod, Gadus morhua: evidence of mate competition and mate choice in a broadcast spawner. Can J Fish Aquat Sci 56:97-104
Ibrayev RA, Ozsoy E, Schrum C, Sur HI (2010) Seasonal variability of the Caspian Sea three-dimensional circulation, sea level and air-sea interaction. Ocean Science 6:311-329

Karlsen Ø, Holm JC (1994) Ultrasonography, a noninvasive method for sex determination in cod (Gadus morhua). J Fish Biol 44:965-971

Kjesbu OS (1989) The spawning activity of cod, Gadus morhua L. J Fish Biol 34:195-206

Kjesbu OS, Righton D, Kruger-Johnsen M, Thorsen A, Michalsen K, Fonn M, Witthames PR (2010) Thermal dynamics of ovarian maturation in Atlantic cod (Gadus morhua). Can J Fish Aquat Sci 67:605-625

- Knutsen H, Olsen EM, Ciannelli L, Espeland SH and others (2007) Egg distribution, bottom topography and smallscale cod population structure in a coastal marine system. Mar Ecol Prog Ser 333:249-255

> Lindholm J, Auster PJ, Knight A (2007) Site fidelity and movement of adult Atlantic cod Gadus morhua at deep boulder reefs in the western Gulf of Maine, USA. Mar Ecol Prog Ser 342:239-247

> Løkkeborg S, Bjordal A, Fernö A (1989) Responses of cod (Gadus morhua) and haddock (Melanogrammus aeglefinus) to baited hooks in the natural environment. Can J Fish Aquat Sci 46:1478-1483

Marteinsdottir G, Gudmundsdottir A, Thorsteinsson V, Stefansson G (2000) Spatial variation in abundance, size composition and viable egg production of spawning cod (Gadus morhua L.) in Icelandic waters. ICES J Mar Sci 57:824-830

Mattson S (1990) Food and feeding habits of fish species over a soft sublittoral bottom in the northeast Atlantic. 1. Cod (Gadus morhua L.) (Gadidae). Sarsia 75:247-260

- Meager JJ, Solbakken T, Utne-Palm AC, Oen T (2005) Effects of turbidity on the reaction distance, search time, and foraging success of juvenile Atlantic cod (Gadus morhua). Can J Fish Aquat Sci 62:1978-1984

$>$ Meager JJ, Skjæraasen JE, Fernö A, Karlsen Ø, Løkkeborg S, Michalsen K, Utskot SO (2009) Vertical dynamics and reproductive behaviour of farmed and wild Atlantic cod Gadus morhua. Mar Ecol Prog Ser 389:233-243

Meager JJ, Skjæraasen JE, Fernö A, Løkkeborg S (2010) Reproductive interactions between fugitive farmed and wild Atlantic cod (Gadus morhua) in the field. Can J Fish Aquat Sci 67:1221-1231

> Michalsen K, Godø OR, Fernö A (1996) Diel variation in the catchability of gadoids and its influence on the reliability of abundance indices. ICES J Mar Sci 53:389-395

Michalsen K, Johannesen E, Bogstad B (2008) Feeding of mature cod (Gadus morhua) on the spawning grounds in Lofoten. ICES J Mar Sci 65:571-580

Morgan MJ, Trippel EA (1996) Skewed sex ratios in spawning shoals of Atlantic cod (Gadus morhua). ICES J Mar Sci 53:820-826

> Neilson JD, Perry RI (1990) Diel vertical migrations of marine fishes: an obligate or facultative process? Adv Mar Biol 26:115-168

Nordeide JT (1998) Coastal cod and north-east Arctic cod: Do they mingle at the spawning grounds in Lofoten? Sarsia 83:373-379

> Nordeide J, Folstad I (2000) Is cod lekking or a promiscuous group spawner? Fish Fish 1:90-93

> Otterå H, Agnalt AL, Jørstad KE (2006) Differences in spawning time of captive Atlantic cod from four regions of Norway, kept under identical conditions. ICES J Mar Sci 
63:216-223

Otterlei E, Nyhammer G, Folkvord A, Stefansson SO (1999) Temperature- and size-dependent growth of larval and early juvenile Atlantic cod (Gadus morhua): a comparative study of Norwegian coastal cod and northeast Arctic cod. Can J Fish Aquat Sci 56:2099-2111

Ottersen G, Sundby S (1995) Effects of temperature, wind and spawning stock biomass on recruitment of ArctoNorwegian cod. Fish Oceanogr 4:278-292

Parejo D, White J, Clobert J, Dreiss A, Danchin E (2007) Blue tits use fledgling quantity and quality as public information in breeding site choice. Ecology 88:2373-2382

Perry AL, Low PJ, Ellis JR, Reynolds JD (2005) Climate change and distribution shifts in marine fishes. Science 308:1912-1915

Pinheiro JC, Bates DM (2000) Mixed-effects models in S and S-PLUS. Springer-Verlag, New York, NY

Pörtner HO, Farrell AP (2008) Ecology, physiology and climate change. Science 322:690-692

> Pörtner HO, Bock C, Knust R, Lannig G, Lucassen M, Mark FC, Sartoris FJ (2008) Cod and climate in a latitudinal cline: physiological analyses of climate effects in marine fishes. Clim Res 37:253-270

Purchase CF, Butts IAE, Alonso-Fernández A, Trippel EA (2010) Thermal reaction norms in sperm performance of Atlantic cod (Gadus morhua). Can J Fish Aquat Sci 67: 498-510

R Development Core Team (2011) R: a language and environment for statistical computing. R Foundation for Statistical Computing, Vienna

Righton DA, Andersen KH, Neat F, Thorsteinsson V and others (2010) Thermal niche of Atlantic cod Gadus morhua: limits, tolerance and optima. Mar Ecol Prog Ser 420:1-13

Robichaud D, Rose GA (2001) Multiyear homing of Atlantic cod to a spawning ground. Can J Fish Aquat Sci 58: 2325-2329

Rose GA (1993) Cod spawning on a migration highway in

Editorial responsibility: Brent Stewart,

San Diego, California, USA the north-west Atlantic. Nature 366:458-461

> Rowe S, Hutchings JA, Skjæraasen JE, Bezanson L (2008) Morphological and behavioural correlates of reproductive success in Atlantic cod Gadus morhua. Mar Ecol Prog Ser 354:257-265

Schmidt KA (2004) Site fidelity in temporally correlated environments enhances population persistence. Ecol Lett $7: 176-184$

> Skjæraasen J, Hutchings J (2010) Shifting reproductive success in a shoal of Atlantic cod, Gadus morhua L. Environ Biol Fishes 88:311-318

> Skjæraasen JE, Salvanes AGV, Karlsen O, Dahle R, Nilsen T, Norberg B (2004) The effect of photoperiod on sexual maturation, appetite and growth in wild Atlantic cod (Gadus morhua L.). Fish Physiol Biochem 30:163-174

Skjæraasen JE, Meager JJ, Karlsen Ø, Mayer I and others (2010) Mating competition between farmed and wild cod Gadus morhua. Mar Ecol Prog Ser 412:247-258

Skjæraasen JE, Meager JJ, Karlsen Ø, Hutchings JA, Fernö A (2011) Extreme spawning-site fidelity in Atlantic cod. ICES J Mar Sci 68:1472-1477

> Strand E, Huse G (2007) Vertical migration in adult Atlantic cod (Gadus morhua). Can J Fish Aquat Sci 64:1747-1760

Sundby S, Nakken O (2008) Spatial shifts in spawning habitats of Arcto-Norwegian cod related to multidecadal climate oscillations and climate change. ICES J Mar Sci 65:953-962

Turuk TN (1973) Diurnal periodicity in feeding and the vertical movements of the Atlantic cod (Gadus morhua L). J Ichthyol 13:275-288

van der Meeren T, Ivannikov VP (2006) Seasonal shift in spawning of Atlantic cod (Gadus morhua L.) by photoperiod manipulation: egg quality in relation to temperature and intensive larval rearing. Aquacult Res 37: 898-913

Wood SN (2006) Generalized additive models: an introduction with R. Chapman \& Hall/CRC, Boca Raton, FL

Submitted: October 5, 2011; Accepted: August 8, 2012 Proofs received from author(s): November 6, 2012 